\title{
DEVELOPMENT OF THE METHODOLOGY OF COMPUTER AIDED DESIGNING OF TAILOR-MADE ORTHESES OF THE TARSAL JOINT
}

\author{
K. Jochymczyk-Woźniak ${ }^{*}$, K. Joszko ${ }^{* *}$, A. Bieniek ${ }^{* * *}$, A. Panuś ${ }^{\dagger}$, R. Czyrnia ${ }^{\ddagger}$
}

\begin{abstract}
This work aimed to develop the methodology of the selection of ortheses using computer aided engineering tools. Within the framework of this research an orthesis model was formulated by means of reverse engineering. Modification of the model was done by cutting the material with a tool in the shape of an ellipse. Next, a multi-variant numerical analysis was conducted, where the geometry and location of the tool were adopted as parameters. Boundary conditions for a static analysis and fatigue analysis were chosen on the basis of gait tests conducted by means of the BTS Smart - a system for a three-dimensional motion analysis. On the basis of the conducted numerical analyses, the most desirable shape of the orthesis was obtained taking into account the orthesis's real lifetime and comfort of use.
\end{abstract}

Keywords: orthoses, strength analysis, motion analysis, 3D scanner

\section{Introduction}

Statistical data concerning health condition of the population of Poland reveal that disabled people make up around $10 \%$ of the whole population. A dominant group of the disabled consists of people with injuries and diseases of the motor organ (55.8\%). This makes a number of almost two million people who need orthopaedic equipment. Such equipment, including ortheses, is defined as 'an apparatus for external use applied with the purpose of modification of features of the body structure and functioning of the nervous system as well as musculoskeletal system' (ISO 8549-1:1989). Properly matched ortheses may not only prevent the development of a defect, but also improve the patient's mobility. In each case the orthesis should be selected individually according to a defect and a degree of locomotor system disorder, which should be assessed on the basis of quantitative gait analysis (Brown et al., 2017, Jurkojć et al., 2009, Michnik et al., 2018, Nowakowska et al., 2016). Parameters which should be taken into consideration are as follows: orthesis stiffness, mass (weight) and lifetime. Such parameters are influenced by the geometry of the orthesis. Nowadays, the selection of geometry is based on orthotists' specialist experience and is conducted by a gradual removal of the orthesis's material until a desirable result is achieved. However, the selection of proper geometry may also be done using numerical modelling, which is broadly applied in biomechanics (Joszko et. al., 2018). Literature encompasses many works concerning the process of proper selection of ortheses for different types of diseases. For instance, the work by Toshiki Kobayashi et al., in which authors present a design of an experimental orthesis AFO. Stiffness of this orthesis is adjustable both at plantar flexion and dorsiflexion. Those authors

\footnotetext{
Katarzyna Jochymczyk-Woźniak, PhD. Eng.: Department of Biomechatronics, Faculty of Biomedical Engeenering, Silesian Univesity of Technology; Poland, Katarzyna.Jochymczyk-Wozniak@polsl.pl

** Kamil Joszko, PhD. DSc. Eng.: Department of Biomechatronics, Faculty of Biomedical Engeenering, Silesian Univesity of Technology; Poland, Kamil.Joszko@polsl.pl

*** Andrzej Bieniek, MSc. Eng.: Department of Biomechatronics, Faculty of Biomedical Engeenering, Silesian Univesity of Technology; Poland, Andrzej.Bieniek@polsl.pl

† Alksandra Panuś, Eng: Students Scientific „BIOKREATYWNI“, Faculty of Biomedical Engeenering, Silesian Univesity of Technology; Poland, olina94@o2.pl

‡ Radosław Czyrnia, MSc.: Centrum Rehabilitacji Fridamedical; Poland, fridamedical@op.pl
} 
presented also the influence of the above-mentioned orthesis on the kinematics of the tarsal joint in patients after stroke. In the researchers' opinion, adjustable stiffness of the AFO orthesis has impact on the kinematics of the patient's gait (Kobayashi et al., 2011). In another work, Deberg et al. showed a process of designing, modelling and the AFO assessment which made use of super-elastic behaviour of a rod made of a shape-memory alloy. In the above-mentioned work, the authors also adjusted stiffness of the orthesis, but this time by means of the above-mentioned rod of the SMA type. Additionally, the authors proved that the change of stiffness of the SMA rods is similar to natural changes in stiffness of the tarsal joint in regular gait. The orthesis eliminated excessive loads on active muscles and allowed the patient to walk in a more natural way as well as feel less tired (Deberg et al., 2014). On the basis of the conducted research on literature as well as initial own investigations and consultations with orthotists, the authors of this article came to the conclusion that one of the key issues in matching individual ortheses of the tarsal joint is the determination of proper stiffness of the orthesis. Another problem is a lack of a complex approach to the selection of ortheses of the tarsal joint (AFO/DAFO) which would take into consideration individual features and needs of the patient in the medical and biomechanical scope. Taking into account the above, this work aimed to develop the methodology of the selection of ortheses using computer aided engineering tools.

\section{Methods}

This paper presents tests supporting the process of preparation of personalized orthopaedic equipment. The methodology of testing was divided into several stages and presented in a block diagram shown in Fig. 1.

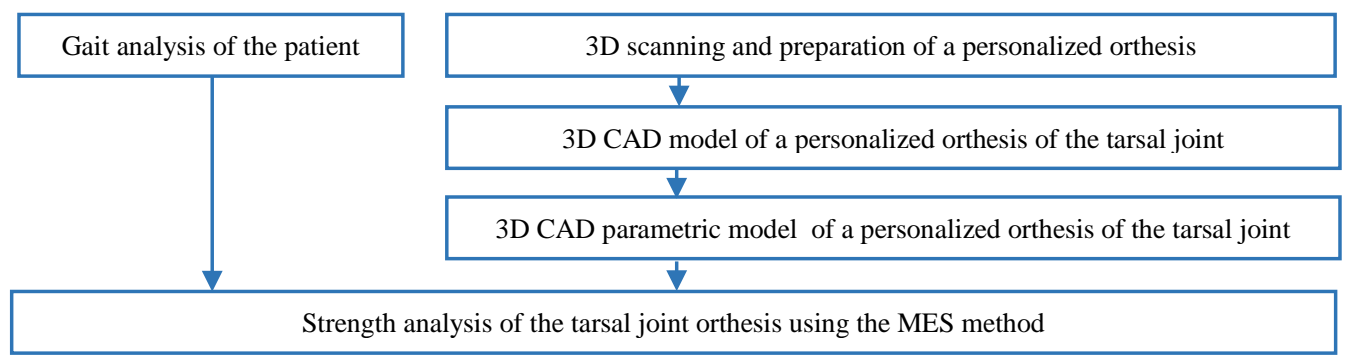

Fig. 1: Methodology of conducted tests

In the first phase of the process of selection of tailor-made ortheses, a 3D scanner was used. It enabled precise determination of geometrical features of the shank surface having contact with the orthesis as well as determination of the orthesis's geometry. Data obtained in the process of creation of a 3D model of the orthesis were used to develop a geometrical model. A manual laser scanner was used in the investigations. It enabled digital recording of the geometry of the measured object. As a result of the scanning process a cloud of points was obtained, which was subjected to triangulation in order to generate a geometrical model and later a discrete one. Figure 4 presents a mesh of points obtained from 3D scanning of the tarsal joint orthesis and its geometrical form.

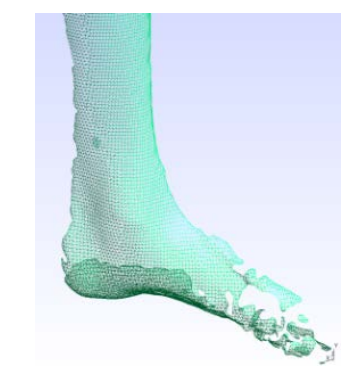

a)

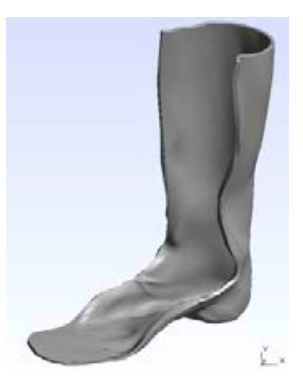

b)

Fig. 2: Results of the scanning process of a personalized orthesis: a) a mesh representing a 3D scan of an orthesis of the patient's tarsal joint, b) a spatial model of the AFO orthesis

The geometry, which had been obtained using methods of reverse engineering, was subjected to the process of stiffness selection by means of removal of the material with a tool having a shape of an ellipse 
(Fig. 3.). In the final stage, a multi-variant numerical analysis was performed in the software programme Ansys Workbench, where the location of the tool and its dimensions constituted the parameters.
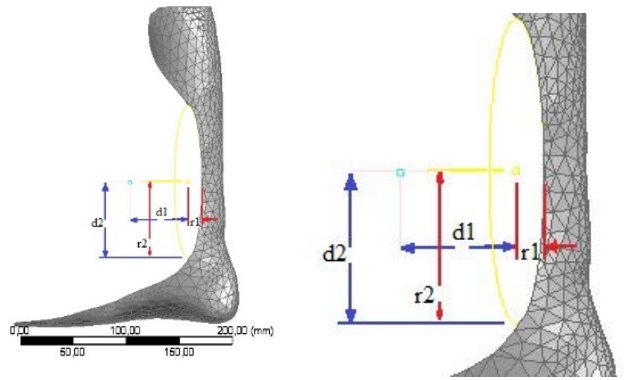

Fig. 3: A geometrical model showing the methodology of orthesis geometry changes

The developed model was discreted by means of surface elements of a thickness of $4 \mathrm{~mm}$, which corresponds to the thickness of the analyzed orthesis. Static and fatigue analyses were performed. Boundary conditions were chosen in such a way as to reflect the worst moment of gait in the context of strength conditions. They were defined as the deprivation of all degrees of freedom in the place of contact of the heel with the ground and flexion of the tarsal joint by 17 degrees (Fig. 4). These conditions were determined on the basis of gait tests (Nowakowska et al., 2016) and therapists' opinions. The fatigue analysis was conducted for the repeated stress and Gerber's hypothesis which is adequate for materials, such as propylene, from which the orthesis was made.

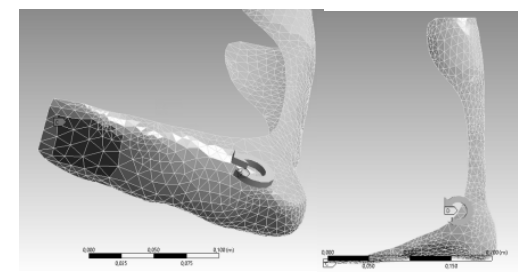

Fig. 4: Boundary conditions

\section{Results}

One thousand and eighty-nine (1089) modifications of the orthesis were analyzed. The volume and number of cycles after which the material would be destroyed were determined. This dependence was presented in Fig. 5b. The relation between the long axis and short ellipse was presented in Fig 5a. The diagrams show the impact of orthesis geometry on its strength parameters. Moreover, the decrease in strength values was observed when the depth of incision was increased and the width of incision decreased. However, no dependence was observed between the height of the incision location and the strength properties in the examined range of changeability of this parameter.
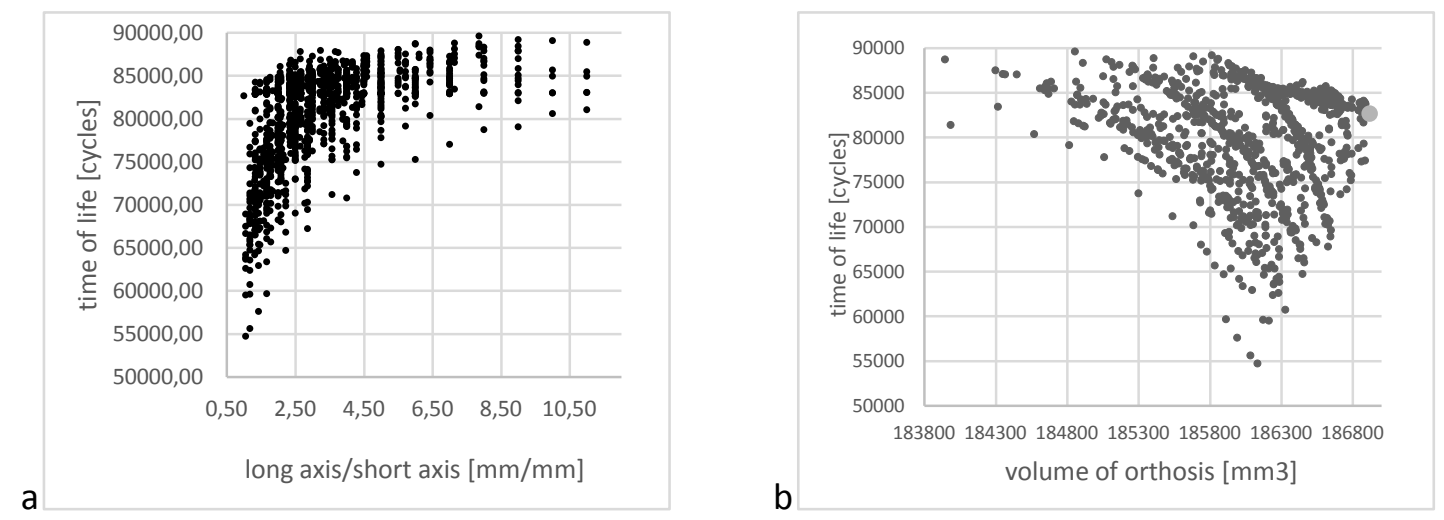

Fig. 5: Dependence of the orthesis lifetime on its geometry 
Occurrence of maximum stresses corresponds to the occurrence of failures in real-life ortheses, which was confirmed by physiotherapists and on the basis of observations of ortheses in use. An example of stress distribution is presented in Fig. 6.
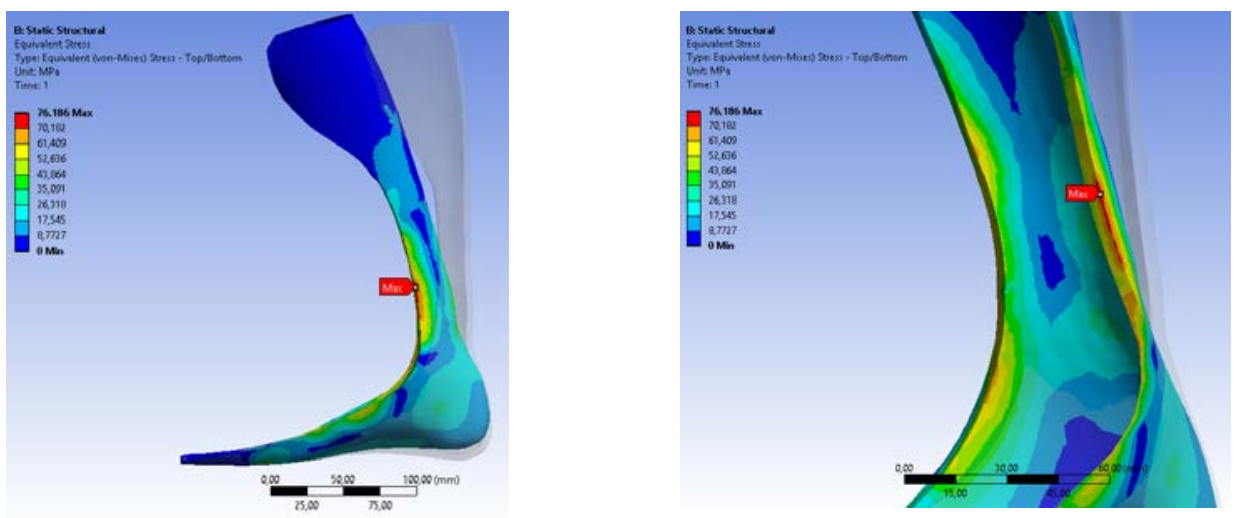

Fig. 6: Distribution of stresses reduced acc. to the Huber-Mises hypothesis

\section{Conclusions}

The presented investigations can be applied in practice. They make it possible to prepare personalized ortheses of the lower limb of the parameters matching the patient's locomotor functions. The initial results confirm the necessity of taking into consideration computer aided engineering methods in the process of preparation of individual tailor-made ortheses. In the present selection process of ortheses, proper stiffness is adjusted in an experimental way by means of a gradual removal of the orthesis material. In such a process it is easy to make a mistake and an excessive removal of the material is irreversible. That is why the selection and matching of a proper orthesis aided by 3D scanning and numerical calculations enable the improvement of the traditional process of selection and taking plaster casts of the lower limb, which has been based so far on the craftsman's laborious work. The new method makes it also possible to lower the costs of manufacturing. Moreover, the process of ortheses selection on the basis of the computer aided engineering tools enables matching the stiffness / elasticity of the orthesis to each patient's individual needs and thus avoiding additional modifications of the structure.

\section{References}

Brown S.E., Russell Esposito E., Wilken J.M. (2017) The effect of ankle foot orthosis alignment on walking in individuals treated for traumatic lower extremity injuries. J. Biomech., 61, pp. 51-57.

Deberg L., Andani M. T., Hosseinipour M. and Elahinia M. (2014) An SMA passive ankle foot orthosis: design, modeling and experimental evaluation, Hindawi Publishing Corporation Smart Materials Research, pp. 1-11.

Joszko K., Gzik M., Wolański W., Gzik-Zroska B., Kawlewska E. (February 2018) Biomechanical evaluation of human lumbar spine in spondylolisthesis, Journal of Applied Biomedicine, 16, pp. 51-58, DOI 10.1016/j.jab004.2017.10.

Jurkojć J., Michnik R., Pauk J. (September 2009) Identification of muscle forces acting in lower limb with use planar and spatial mathematical model, Journal of Vibroengineering, 11, 3, pp. 566-570.

Kobayashi T., Leung A. K. L., Akazawa Y. and Hutchins S. W. (2011) Design of a stiffness-adjustable ankle-foot orthosis and its effect on ankle joint kinematics in patients with stroke. Gait \& Posture, 33, pp. 721-723.

Michnik, R., Nowakowska, K., Jurkojć, J., Jochymczyk-Woźniak, K., Kopyta, I. (2017) Motor functions assessment method based on energy changes in gait cycle. Acta of Bioengineering and Biomechanics, 19, 4, pp. 63-75.

Nowakowska, K., Michnik, R., Jochymczyk-Woźniak, K., Jurkojć, J., Mandera, M. and Kopyta, I. (2016) Application of gait index assessment to monitor the treatment progress in patients with cerebral palsy. In Information Technologies in Medicine 5th International Conference (ed. Piętka E., Badura P., Kawa J., Więcławek W.), Advances in Intelligent System and Computing, 472, 2, 75-85, Cham: Springer.

ISO 8549-1:1989 Prosthetics and orthotics - Vocabulary - Part 1: General terms for ex-ternal limb prostheses and external orthoses.2.1. Style - Chapter 1 EM 2017. 